\title{
The Human Brain Processes Syntax in the Absence of Conscious Awareness
}

\author{
Laura Batterink and Helen J. Neville \\ Department of Psychology, University of Oregon, Eugene, Oregon 97403-1227
}

Syntax is the core computational component of language. A longstanding idea about syntactic processing is that it is generally not available to conscious access, operating autonomously and automatically. However, there is little direct neurocognitive evidence on this issue. By measuring event-related potentials while human observers performed a novel cross-modal distraction task, we demonstrated that syntactic violations that were not consciously detected nonetheless produced a characteristic early neural response pattern, and also significantly delayed reaction times to a concurrent task. This early neural response was distinct from later neural activity that was observed only to syntactic violations that were consciously detected. These findings provide direct evidence that the human brain reacts to violations of syntax even when these violations are not consciously detected, indicating that even highly complex computational processes such as syntactic processing can occur outside the narrow window of conscious awareness.

\section{Introduction}

Language is often hailed as a hallmark of human cognition, and syntax is the defining characteristic of this ability, setting human languages apart from other forms of animal communication (Hauser et al., 2002; Pinker and Jackendoff, 2005; Premack, 2007). Syntax refers to a set of rules that govern how words in a language can be combined, which allow an infinite number of meaningful expressions to be created from a finite vocabulary. Syntactic processing is one of the most complex cognitive tasks that humans routinely engage in: languages contain countless syntactic rules, which must be accessed rapidly and simultaneously during normal language processing. Despite this complexity, language is generally spoken and understood with little apparent effort, and a longstanding hypothesis is that syntactic processing occurs outside of conscious awareness, relying upon computational mechanisms that are autonomous and automatic (Fodor, 1983; Ullman, 2001; Friederici, 2002; Paradis, 2004). However, the claim that syntactic processing occurs unconsciously has never been directly tested, perhaps due to the methodological difficulty of examining this issue.

We developed a novel approach to address this question, in which we recorded event-related brain potentials (ERPs) to syntactic violations processed with and without conscious awareness. We manipulated awareness of syntactic violations by using a cross-model distraction task, in which an auditory

\footnotetext{
Received Feb. 9, 2013; revised March 27, 2013; accepted April 10, 2013.

Author contributions: L.B. and H.N. designed research; L.B. performed research; L.B. analyzed data; L.B. and H.N. wrote the paper.

This work was supported by NIH Grant DC 000128. We thank Mandy Hampton-Wray, Christina Karns, Eric Pakulak, and Yoshiko Yamada for their comments on an earlier version of this manuscript.

The authors declare no competing financial interests.

Correspondence should be addressed to Laura Batterink, Lewis Integrative Science Building, University of Oregon, 1440 Franklin Boulevard, Eugene, Oregon 97403-1227. E-mail: Ibatteri@uoregon.edu.

DOI:10.1523/JNEUROSCI.0618-13.2013

Copyright $\odot 2013$ the authors $\quad 0270-6474 / 13 / 338528-06 \$ 15.00 / 0$
}

tone was presented either immediately before or well after the onset of a visually presented violation (see Fig. $1 A$ ). Following the same logic as a cross-modal attentional blink design (Dell'Acqua et al., 2003), we reasoned that processing of the tone should tax limited-capacity, postperceptual resources, preventing the perceptual representation of the syntactic violation from being consolidated into working memory and reaching awareness (Chun and Potter, 1995; Jolicoeur and Dell'Acqua, 1998). Syntactic violations preceded by an auditory tone should thus be detected less often than syntactic violations presented well before the tone, enabling us to manipulate awareness of syntactic violations while keeping the physical language stimuli identical. In previous studies we followed a similar approach to investigating the contribution of awareness to different neural mechanisms supporting language processing (Batterink et al., 2009, 2012).

Syntactic violations typically elicit a biphasic ERP response, consisting of an earlier negativity usually maximal over left anterior sites, termed the left anterior negativity and a later positivity, broadly distributed over posterior sites, known as the P600 (Neville et al., 1991; Osterhout and Holcomb, 1992; Friederici et al., 1993). The earlier negativity is thought to index more automatic mechanisms mediating syntactic processing, while the posterior positivity is hypothesized to reflect later, more controlled mechanisms (Friederici, 2002). Prior research using task and probability manipulations suggests that the earlier negative response is less influenced by attention than the later positivity (Gunter et al., 1997; Hahne and Friederici, 1999; 2002), but the role of conscious awareness in generating these two components has not been directly assessed. We hypothesized that if the brain processes syntax implicitly, in the absence of awareness, undetected syntactic violations should elicit an early anterior negativity, while only consciously detected violations should elicit a posterior positivity. In contrast, if the brain is not capable of processing 
A

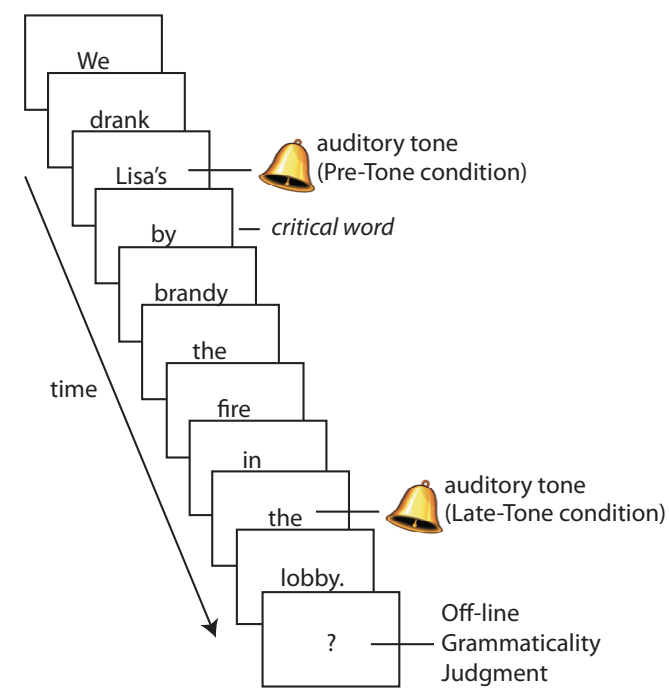

B

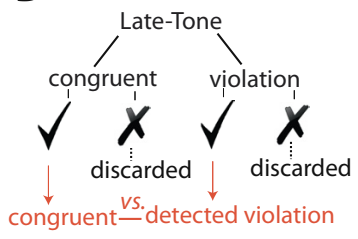

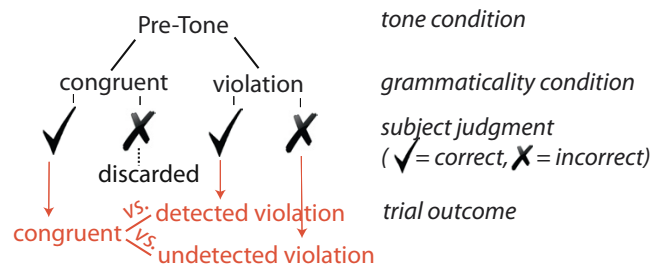

undetected violation

Figure 1. Example stimuli and analysis strategy. $A$, Sequence of events in a typical violation trial. One auditory tone was played during each trial, either immediately before the critical word (Pre-Tone condition) or well after the critical word (Late-Tone condition). $\boldsymbol{B}$, Schematic diagram showing how trials in each condition were divided for analysis.

syntax implicitly, undetected syntactic violations should not elicit a reliable ERP effect.

\section{Materials and Methods}

Participants. A total of 45 right-handed, neurologically normal native English speakers ( 33 female; age range, $18-30$ years) participated in this study. Two participants did not complete the second session of the study and were excluded from all analyses. Only participants who had a sufficient number of trials $(\geq 13)$ in all conditions were included in analyses, to allow for direct comparisons across conditions, resulting in a final sample of 24 participants.

Stimuli. Because the identification of word category information (e.g., whether a word is a noun, verb, preposition, etc.) appears to be among the fastest subprocesses that occur during syntactic processing (Neville et al., 1991; Friederici, 2002), we presented participants with word category violations, in which a preposition immediately followed a possessive noun (e.g., "*We drank Lisa's by brandy the fire in the lobby"). Each violation sentence was matched with a corresponding syntactically congruent control sentence, in which the critical preposition word occurred in a congruent context, following a noun placed after the possessive noun (e.g., "We drank Lisa's brandy by the fire in the lobby"). Stimuli were counterbalanced such that each participant saw only the congruent or violation version of a given sentences. Participants were presented with a total of 280 experimental sentences, 70 in each tone condition (Pre-Tone, Late-Tone) by syntactic condition (violation, congruent control) cell.

An additional 560 sentences, not analyzed here, were pseudorandomly intermixed with the 280 experimental sentences; half of these additional sentences contained other types of grammatical violations (violations of tense agreement and subject-verb agreement).

Auditory stimuli were $50 \mathrm{~ms}$ pure tones, played at a comfortable listening level $(70 \mathrm{~dB}$ ), with frequencies of 550, 900, and $1400 \mathrm{~Hz}$ (cf. Dell'Acqua et al., 2003). To avoid cueing participants to the presence of an upcoming violation, for half of the trials in the congruent Pre-Tone condition the tone was played $200 \mathrm{~ms}$ before the noun following the possessive noun in the sentence, the same placement as the violation sentences, rather than 200 ms before the critical word $(\mathrm{CW})$. These trials were simply designed to reduce the predictability of the tone placement and sentence violation status, and were not included in ERP analyses.

Procedure. Sentences were presented visually one word at a time (stimulus onset asynchrony, $300 \mathrm{~ms}$; Fig. 1A). On each trial, an auditory tone was presented either $200 \mathrm{~ms}$ before the onset of the critical violation or congruent control word, termed the "Pre-Tone" condition, or well after critical word onset (mean, 1300 $\mathrm{ms}$; range, $700-3100 \mathrm{~ms}$ ), referred to as the "Late-Tone" condition. Using a keypad, participants responded as quickly as possible to the auditory tone, indicating its pitch (low, medium, or high), and made an offline judgment about whether the sentence was grammatical or ungrammatical.

ERP recording and analysis. EEG recordings were made with a 64-channel Active Two system (Biosemi), using our standard recording and analysis procedures (Batterink and Neville, 2011). Epochs were extracted from -300 to $1200 \mathrm{~ms}$ relative to stimulus onset. Data were baseline corrected from -300 to $-200 \mathrm{~ms}$ preceding stimulus onset, which corresponds to the $100 \mathrm{~ms}$ period preceding the tone in the Pre-Tone condition, to avoid contaminating the baseline period with the auditory evoked potential elicited by the tone.

For statistical analyses, amplitudes were averaged across neighboring electrodes to form nine channel groups of interest. Time windows for statistical analysis were selected based on visual inspection of the data as well as on previous published findings (early window, 100-400 ms; late window, 600-1200 $\mathrm{ms}$ ). Because the late positivity in the Pre-Tone correctly detected violation condition began considerably later than the late positivity in the Late-Tone condition, earlier (600-900 ms) and later time windows (900-1200 ms) were also selected within the original 600-1200 ms window to better characterize and compare these effects. For negative effects observed in both the early and later time windows, analyses were conducted over anterior and central regions, because these effects are generally more pronounced over anterior scalp (Neville et al., 1991; Friederici, 2002). For the posterior positivities, analyses were conducted over posterior sites. Data were normalized for all distributional comparisons across conditions to account for amplitude differences (McCarthy and Wood, 1985).

ANOVA was used for all statistical tests, with violation condition (congruent, violation), anterior/posterior (anterior, central, posterior), and hemisphere (left, midline, right) as factors. Greenhouse-Geisser corrections are reported for factors with more than two levels. All subjects included in averages had at least 13 trials in all conditions. In the LateTone Detected condition, grand averages consisted of 1370 congruent and 1312 violation trials. In the Pre-Tone Detected and Undetected conditions, trial numbers ranged from 674 to 753 .

To examine whether there was a clear separation between the early and late negativities observed in the Pre-Tone Undetected violation condition, an onset analysis was conducted. Repeated-measures ANOVAs were performed on adjacent $20 \mathrm{~ms}$ bins, moving by a $10 \mathrm{~ms}$ time window, across anterior and central electrode regions. The onset and offset were defined as the first and last of three consecutive significant (i.e., $p<0.05)$ ANOVAs, respectively. In addition, because the word before the critical word was not identical in the congruent and violation conditions, an additional moving window analysis was conducted from -200 (the end of the baseline correc- 


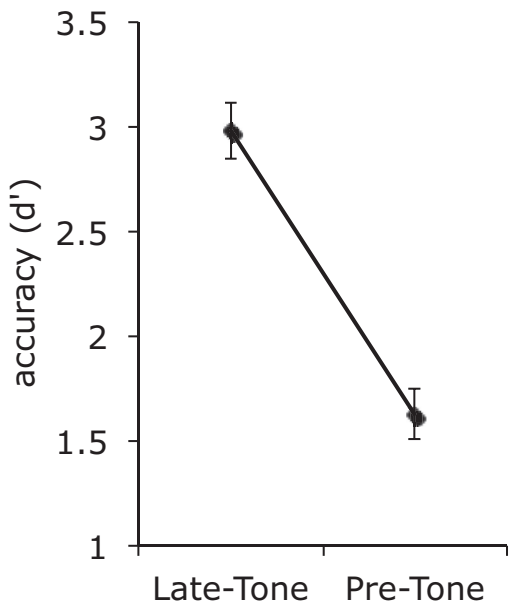

Figure 2. Mean performance on the grammaticality judgment task $\left(d^{\prime}\right)$, as a function of tone condition $(n=24)$. Error bars represent SEM.

tion period) to $100 \mathrm{~ms}$ across all electrodes to quantify potential condition differences occurring before our selected early time window (100-400 ms).

\section{Results \\ Behavioral results}

Accuracy

Awareness of syntactic violations was significantly reduced in the Pre-Tone condition relative to the Late-Tone condition $\left(F_{(1,23)}=\right.$ $106.0, p<0.0001$; Fig. 2). Specifically, $89 \%$ of syntactic violations were detected in the Late-Tone condition $\left(d^{\prime}=3.0\right)$, while only $51 \%$ of violations were detected in the Pre-Tone condition $\left(d^{\prime}=\right.$ 1.6). The false alarm rate (in which participants incorrectly rejected syntactically acceptable sentences) was $6 \%$ for both PreTone and Late-Tone conditions. Overall accuracy of tone discrimination was $92 \%$. These results confirm that this paradigm effectively manipulated subjective awareness of syntactic violations while keeping the physical language stimuli constant across conditions.

\section{Reaction time}

We analyzed median RTs to auditory tones in the Pre-Tone condition to investigate whether processing of syntactic violations that were not consciously detected exerted an implicit behavioral cost. Consistent with this hypothesis, the median RT to tones that preceded undetected syntactic violations (712 ms; SD, $137 \mathrm{~ms}$ ) was significantly longer than the median RT to tones that preceded syntactically congruent control words $(678 \mathrm{~ms}$; SD, 114 ms; $\left.F_{(1,23)}=9.43, p=0.005\right)$. Note that participants endorsed sentences in both these conditions, meaning that only the actual presence or absence of a violation differentiates them. This result suggests that the presence of a syntactic violation disrupted online processing, even though participants were unaware of it.

\section{ERP results}

ERP waveforms to the three experimental conditions of interest (correctly detected Late-Tone violations, correctly detected PreTone violations, and undetected Pre-Tone violations) are shown in Figure 3. In all cases, syntactic violations are compared to correctly judged syntactically congruent control words, within the same tone condition (see Fig. 1B). Correctly detected LateTone violations elicited the hallmark biphasic response: an early anterior negativity followed by a later positivity, distributed over posterior electrodes $\left(100-400 \mathrm{~ms}\right.$ window, $F_{(1,23)}=4.52, p=$ $0.044 ; 600-1200$ window, $F_{(1,23)}=27.6, p<0.001 ;$ Fig. $\left.3 A\right)$. This

\section{A Late-Tone, Violation Detected}

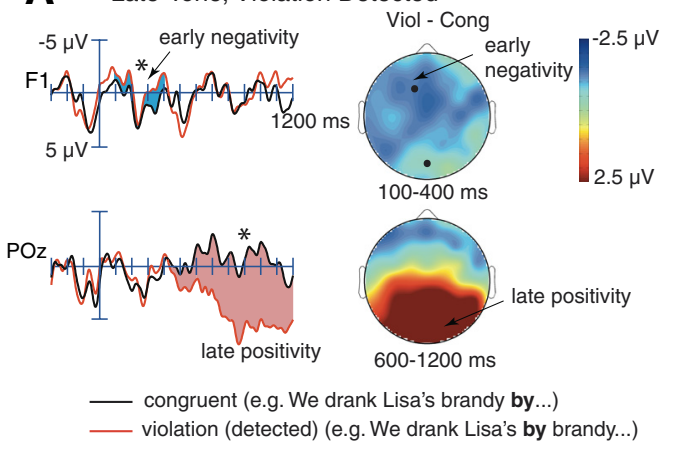

B Pre-Tone, Violation Detected

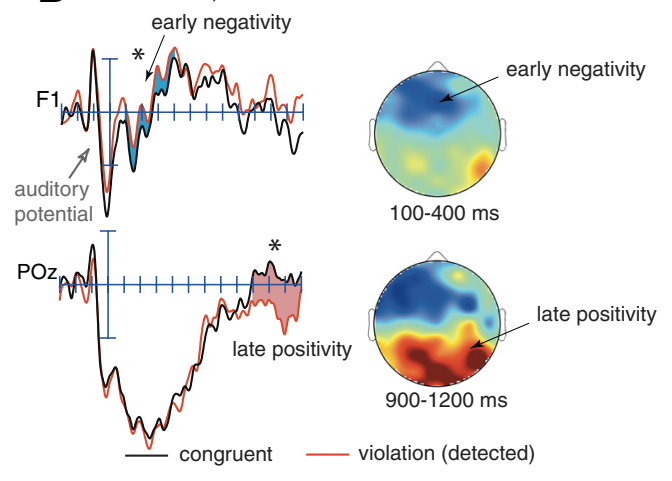

C Pre-Tone, Violation Undetected

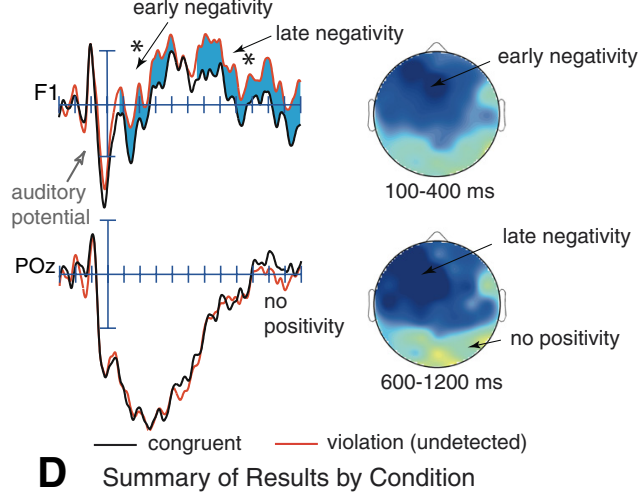

\begin{tabular}{|c|c|c|c|}
\hline Condition & $\begin{array}{c}100-400 \mathrm{~ms} \\
\text { (Anterior Sites) }\end{array}$ & $\begin{array}{c}600-1200 \mathrm{~ms} \\
\text { (Anterior Sites) }\end{array}$ & $\begin{array}{c}900-1200 \mathrm{~ms} \\
\text { (Posterior Sites) }\end{array}$ \\
\hline Late-Tone Detected & $-1.1 \mu \mathrm{V} *$ & $-0.41 \mu \mathrm{V}$, ns & $3.2 \mu \mathrm{V} *$ \\
Pre-Tone Detected & $-0.94 \mu \mathrm{V}^{*}$ & $-0.97 \mu \mathrm{V}, \mathrm{ns}$ & $1.5 \mu \mathrm{V}$ \\
Pre-Tone Undetected & $-1.7 \mu \mathrm{V} *$ & $-2.0 \mu \mathrm{V} *$ & $-0.49 \mu \mathrm{V}$, ns \\
\hline
\end{tabular}

Figure 3. ERP waveforms, averaged across participants ( $n=24)$ at electrodes F1 and POZ. Scalp distributions of the difference between violation words and congruent control words, averaged across specified time windows, are shown on the right. Approximate electrode locations are denoted with black dots on the uppermost scalp map. Asterisks denote a significant effect $(p<0.05)$. $A$, ERPs elicited by correctly detected violations and correctly endorsed congruent control words in the Late-Tone condition. $\boldsymbol{B}$, ERPs elicited by correctly detected violations and correctly endorsed congruent control words in the Pre-Tone condition. The auditory evoked potential to the tones can be observed prior to stimulus onset. C, ERPs elicited by undetected violations and correctly endorsed correct congruent words in the Pre-Tone condition. $\boldsymbol{D}$, Table summarizing results by condition and time window. Values indicate the amplitude of the violation effect (violation - canonical), while shaded colors indicate the polarity (blue, negative; red, positive).

finding confirms that our paradigm produces results that are comparable to many previous ERP studies of syntactic processing (Neville et al., 1991; Osterhout and Holcomb, 1992; Friederici et al., 1993; Hahne and Friederici, 1999; Friederici, 2002). Correctly 
detected Pre-Tone violations produced a similar pattern, consisting of an early negativity, maximal over left anterior scalp sites, followed by a later positivity $\left(100-400 \mathrm{~ms}\right.$ window, $F_{(1,23)}=6.72$, $p=0.016$; violation by hemisphere, $F_{(2,46)}=3.51, p=0.041$; $900-1200 \mathrm{~ms}, F_{(1,23)}=5.46, p=0.028$; Fig. $\left.3 B\right)$. While the amplitude of the early negativity in the Pre-Tone condition was not significantly different from the negativity in the Late-Tone condition $\left(F_{(1,23)}=0.10, p=0.75\right)$, the posterior positive effect began later and was significantly reduced in amplitude $(600-$ $1200 \mathrm{~ms}, F_{(1,23)}=12.2, p=0.002 ; 900-1200 \mathrm{~ms}, F_{(1,23)}=4.61$, $p<0.043)$. This reduction may be attributed to refractory period effects caused by the auditory tone, which elicited an auditory evoked potential and subsequent P300 in the time window surrounding the onset of the syntactic violation (Woods et al., 1980).

The crucial condition of interest was comprised of undetected violations in the Pre-Tone condition. Critically, these undetected violations also elicited an early negativity, maximal over left anterior regions $\left(100-400 \mathrm{~ms}, F_{(1,23)}=13.5, p<0.001\right.$; violation by hemisphere, $F_{(2,46)}=3.33, p=0.050$; Fig. $\left.3 C\right)$. The amplitude of this negativity was marginally greater than the negativity elicited in the Pre-Tone Detected condition $\left(F_{(1,23)}=3.21, p=0.087\right)$, but not significantly different from the negativity in the LateTone Detected condition $\left(F_{(1,23)}=1.03, p=0.32\right)$. No later posterior positivity was observed in this condition $(900-1200 \mathrm{~ms}$, $\left.F_{(1,23)}=0.55, p=0.47\right)$; in contrast, a second negative effect was observed $\left(600-1200 \mathrm{~ms}, F_{(1,23)}=16.0, p=0.001\right.$; violation by hemisphere, $\left.F_{(2,46)}=4.27, p=0.021\right)$. Onset analyses revealed that the early negativity offset at $390 \mathrm{~ms}$, while the later negativity began at $540 \mathrm{~ms}$ and continued to the end of the averaging epoch (1200 ms). The distributions of these two negativities were not significantly different (all $p$ values $>0.6$ ).

The distribution of the early negative effects was not significantly different across the three conditions (100-400 ms, condition by anterior/posterior, $F_{(4,92)}=1.73, p=0.19$; condition by hemisphere, $\left.F_{(4,92)}=0.42, p=0.77\right)$. Planned contrasts confirmed that the Late-Tone Detected violation effect was not different from the Pre-Tone Detected violation effect (all distributional interactions $p$ values $>0.14$ ), and that the Pre-Tone Undetected violation effect did not differ from the Pre-Tone Detected violation effect (all distributional interactions $p$ values $>0.7$ ). In contrast, the late posterior positivity elicited by Late-Tone violations was more medial and marginally more posterior than the effect elicited by Pre-Tone Detected violations (900-1200 ms, condition by anterior/posterior, $F_{(2,46)}=3.24, p=0.073$; condition by hemisphere, $\left.F_{(2,46)}=5.12, p=0.011\right)$.

Results from the moving window analysis conducted from -200 to $100 \mathrm{~ms}$ revealed that some transient condition differences emerged before our selected early time window (100-400 $\mathrm{ms})$. Congruent and violation ERPs were significantly different from -160 to $-100 \mathrm{~ms}$ and from -50 to $0 \mathrm{~ms}$ in the Late-Tone condition, from -70 to $-10 \mathrm{~ms}$ and from 10 to $50 \mathrm{~ms}$ in the Pre-Tone Detected condition, and from -160 to $-120 \mathrm{~ms}$ and from -10 to $40 \mathrm{~ms}$ in the Pre-Tone Undetected condition. No single time point between -200 and $100 \mathrm{~ms}$ showed significant condition differences across all three experimental conditions. These early ERP differences may be attributed to the fact that the word before the critical word was not identical in the congruent and violation conditions, an issue that we will return to in the discussion section.

\section{Discussion}

In summary, both detected and undetected syntactic violations elicited an early negative effect, which thus represents a neural marker of implicit syntactic processing. In contrast, only detected violations evoked a later positivity, which appears to index syntactic processing that is explicit in nature, requiring conscious awareness for its operation. Undetected syntactic violations also significantly delayed reaction times to the concurrent tone task, providing converging behavioral evidence of a dissociation between implicit and explicit syntactic processing.

Our findings demonstrate that the brain processes syntactic information implicitly, in the absence of awareness. While other aspects of language, such as semantics and phonology, can also be processed implicitly (Dehaene et al., 1998; Wilson et al., 2011), the present data represent the first direct evidence that implicit mechanisms also play a role in the processing of syntax, the core computational component of language. This implicit syntax processing subsystem appears to rely upon neural mechanisms that are dissociable from those mediating explicit syntactic processing, as indicated by the distinct latency and distribution of their associated ERP effects. These implicit mechanisms are activated quickly and automatically, in the absence of conscious awareness, and may be more specialized than the mechanisms subserving controlled, explicit syntactic processing, which are likely not specific to language (Patel et al., 1998; Christiansen et al., 2011; Tabullo et al., 2011).

Localization studies of the early negativity and posterior positivity support this view. Source localization studies using magnetoencephalography have suggested that the early negativity is generated by inferior frontal cortex and anterior temporal cortex, possibly the planum porale, with a clear dominance in the left hemisphere (Knösche et al., 1999; Friederici et al., 200). These findings converge with ERP studies of lesion patients, which have shown that the early negativity is absent in patients with lesions in the left inferior frontal gyrus and the left anterior temporal region (Friederici and Kotz, 2003). In contrast, the posterior positivity has been localized to bilateral posterior temporal regions (Service et al., 2007), with some lesion data suggesting that the basal ganglia may also be involved (Frisch et al., 2003). Together, the finding that the early negativity is strongly left lateralized while the posterior positivity is bilateral is consistent with the idea that the early negativity reflects mechanisms that are specific to language, while the posterior positivity may index domain-general, nonlinguistic processes such as context-updating, monitoring, or working memory (Service et al., 2007). These findings are also in line with the hypothesis that the early anterior negativity is an index of more automatic mechanisms mediating syntactic processing, while the posterior positivity reflects later, more controlled mechanisms (Friederici, 2002).

One interesting and unexpected finding revealed by the present study is that undetected violations elicited a marginally more robust earlier negativity than detected violations $(p=0.087)$ as well as an additional robust late negativity. While this late negativity occurred within the same latency range as the posterior positive effects, it did not contribute to conscious awareness of syntactic violations, suggesting that computations performed by certain specific neural systems do not reach awareness, regardless of when they take place. Furthermore, the late negativity was not significantly different in distribution from the early negativity (Fig. 3C), suggesting that these effects are mediated by the same neural substrates and represent a common ongoing process. These observations raise the intriguing possibility that the engagement of explicit mechanisms actively suppresses or "resets" the operation of implicit mechanisms during the normal course of syntactic processing. Under normal circumstances, first-pass syntactic parsing processes may occur automatically in left- 
lateralized language regions, without requiring conscious awareness. If a parsing difficulty is encountered, domain-general mechanisms that require conscious awareness, indexed by the late positivity, may be recruited to reanalyze and repair the syntactic error. This transfer of information from one system to the other when a syntactic problem is experienced may represent an important evolutionary adaptation, freeing left hemisphere language regions to process further input and thereby allowing the brain to effortlessly keep up with the rapid pace of natural speech. However, if explicit, domain-general resources are not available, as occurred in our paradigm when a syntactic violation failed to reach awareness, this transfer of information may be prevented from occurring. In this situation, the implicit system may fail to disengage, continuing to process the syntactic violation rather than preparing for new incoming input. This explanation converges with evidence from human and animal studies showing that implicit and explicit processing systems can interact competitively (Poldrack et al., 2001; Poldrack and Packard, 2003; Fletcher et al., 2005).

One final methodological point concerns the potential impact of pre-CW differences between the congruent and violation sentences on the observed ERPs. Violations of phrase structure occur when the syntactic category of a word is structurally uninterpretable given the preceding context. Due to the nature of these types of violations, the context before the critical word cannot be identical across congruent and violation conditions if the critical word itself is held constant (Steinhauer and Drury, 2012). In the present study, we minimized the potential impact of pre-CW differences by using the possessive clitic 's (e.g., "Lisa's") for the word preceding the critical word $(\mathrm{CW}-1)$ in the violation condition, ensuring that the $\mathrm{CW}-1$ word was open-class in both congruent and violations conditions (Neville et al., 1992). Nonetheless, as can be observed most clearly in the Late-Tone condition (Fig. 3A), some subtle pre-onset condition differences did occur, which is most likely due to the fact that nonidentical $\mathrm{CW}-1$ words were presented in congruent and violation sentences. However, it is unlikely that these pre-CW condition differences significantly modulated or altered our main effects of interest (the early negativity and late positivity). First, the magnitude of these pre-CW differences was small. ERP differences before $100 \mathrm{~ms}$ failed to reach statistical significance except for short, limited time windows that did not show a consistent overlap across the three experimental conditions (Late-Tone Detected, Pre-Tone Detected, and Pre-Tone Undetected), and pre-CW condition differences were considerably smaller in amplitude than either the early negativity or late posterior positivity (Fig. 3). Thus, even if ERP effects due to pre-CW condition differences continued into our time windows of interest (e.g., 100$400 \mathrm{~ms}$ ), they were likely limited to slight amplitude modulations of the underlying violation-related components. Second, it is worth noting that the violation effects reported here (the early negativity and later positivity) are in line with a large number of previous studies that have used a wide range of different paradigms and syntactic violation types (including syntactic violations in which the pre-CW context was balanced across conditions) (for review, see Friederici, 2011). Both the latencies and distributions of our effects are consistent with these prior findings, providing additional evidence that our effects primarily reflect the brain's response to a syntactic violation, rather than subtle differences in the CW -1 word between conditions.

In conclusion, our findings show that the human brain is exquisitely equipped to process language and its regularities. It has long been noted that humans can comprehend and use their native language with apparent effortlessness, despite the enormous complexity involved in this task. One reason for this may be that at least a portion of the mental computations necessary for language processing take place outside of awareness, leaving only a limited subset of processes for the conscious mind to manage. These findings underscore the importance of implicit cognition, demonstrating that even highly complex computations can be processed outside the narrow window of conscious awareness.

\section{References}

Batterink L, Neville H (2011) Implicit and explicit mechanisms of word learning in a narrative context: an event-related potential study. J Cogn Neurosci 23:3181-3196. CrossRef Medline

Batterink L, Karns CM, Yamada Y, Neville H (2009) The role of awareness in semantic and syntactic processing: an ERP attentional blink study. J Cogn Neurosci 22:2514-2529. Medline

Batterink L, Karns CM, Neville H (2012) Dissociable mechanisms supporting awareness: the $\mathrm{P} 300$ and gamma in a linguistic attentional blink task. Cereb Cortex 22:2733-2744. CrossRef Medline

Christiansen MH, Conway CM, Onnis L (2011) Similar neural correlates for language and sequential learning: evidence from event-related brain potentials. Lang Cogn Proc 27:231-256.

Chun MM, Potter MC (1995) A two-stage model for multiple target detection in rapid serial visual presentation. J Exp Psychol Hum Percept Perform 21:109-127. CrossRef Medline

Dehaene S, Naccache L, Le Clec'H G, Koechlin E, Mueller M, DehaeneLambertz G, van de Moortele PF, Le Bihan D (1998) Imaging unconscious semantic priming. Nature 395:597-600. CrossRef Medline

Dell'Acqua R, Jolicoeur P, Pesciarelli F, Job RC, Palomba D (2003) Electrophysiological evidence of visual encoding deficits in a cross-modal attentional blink paradigm. Psychophysiology 40:629-639. CrossRef Medline

Fletcher PC, Zafiris O, Frith CD, Honey RA, Corlett PR, Zilles K, Fink GR (2005) On the benefits of not trying: Brain activity and connectivity reflecting the interactions of explicit and implicit sequence learning. Cereb Cortex 15:1002-1015. Medline

Fodor JA (1983) The modularity of mind. Cambridge, MA: MIT.

Friederici AD (2002) Towards a neural basis of auditory sentence processing. Trends Neurosci 6:78-84. CrossRef

Friederici AD (2011) The brain basis of language processing: from structure to function. Physiol Rev 91:1357-1392. CrossRef Medline

Friederici AD, Kotz SA (2003) The brain basis of syntactic processes: functional imaging and lesion studies. Neuroimage 20:S8-S17. CrossRef Medline

Friederici A, Pfeifer E, Hahne A (1993) Event-related brain potentials during natural speech processing: Effects of semantic, morphological and syntactic violations. Cog Brain Res 1:183-192. CrossRef

Friederici AD, Wang Y, Herrmann CS, Maess B, Oertel U (2000) Localization of early syntactic processes in frontal and temporal cortical areas: a magnetoencephalographic study. Hum Brain Mapp 11:1-11. CrossRef Medline

Frisch S, Kotz SA, von Cramon DY, Friederici AD (2003) Why the P600 is not just a P300: the role of the basal ganglia. Clin Neurophysiol 114:336340. CrossRef Medline

Gunter TC, Stowe LA, Mulder G (1997) When syntax meets semantics. Psychophysiology 34:660-676. CrossRef Medline

Hahne A, Friederici A (2002) Differential task effects on semantic and syntactic processes as revealed by ERPs. Cog Brain Res 13:339-346. CrossRef

Hahne A, Friederici AD (1999) Electrophysiological evidence for two steps in syntactic analysis: early automatic and late controlled processes. J Cogn Neurosci 11:194-205. CrossRef Medline

Hauser MD, Chomsky N, FitchW T (2002) The faculty of language: what is it, who has it, and how did it evolve? Science 298:1569-1579. CrossRef Medline

Jolicoeur P, Dell'Acqua R (1998) The demonstration of short-term consolidation. Cog Psych 36:138-202. CrossRef

Knösche TR, Maess B, Friederici AD (1999) Processing of syntactic information monitored by brain surface current density mapping based on MEG. Brain Topogr 12:75-87. CrossRef Medline

McCarthy G, Wood CC (1985) Scalp distributions of event-related potentials: an ambiguity associated with analysis of variance models. Electroencephalogr Clin Neurophysiol 62:203-208. CrossRef Medline 
Neville HJ, Nicol JL, Barss A, Forster KI, Garrett MF (1991) Syntactically based sentence processing classes: evidence from event-related brain potentials. J Cogn Neurosci 3:151-165. CrossRef

Neville HJ, Mills DL, Lawson DS (1992) Fractionating language: different neural systems with different sensitive periods. Cereb Cortex 2:244-258. CrossRef Medline

Osterhout L, Holcomb P (1992) Event-related brain potentials elicited by syntactic anomaly. J Mem Lang 31:785-801. CrossRef

Paradis M (2004) A neurolinguistic theory of bilingualism. Philadelphia: John Benjamins.

Patel AD, Gibson E, Ratner J, Besson M, Holcomb PJ (1998) Processing syntactic relations in language and music: an event-related potential study. J Cogn Neurosci 10:717-733. CrossRef Medline

Pinker S, Jackendoff R (2005) The faculty of language: what's special about it? Cognition 95:201-236. CrossRef Medline

Poldrack RA, Packard MG (2003) Competition among multiple memory systems: converging evidence from animal and human brain studies. Neuropsychologia 41:245-251. CrossRef Medline

Poldrack RA, Clark J, Paré-Blagoev EJ, Shohamy D, Creso Moyano J, Myers C, Gluck MA (2001) Interactive memory systems in the human brain. Nature 414:546-550. CrossRef Medline
Premack D (2007) Human and animal cognition: continuity and discontinuity. Proc Natl Acad Sci U S A 104:13861-13867. CrossRef Medline

Service E, Helenius P, Maury S, Salmelin R (2007) Localization of syntactic and semantic brain responses using magnetoencephalography. J Cogn Neurosci 19:1193-1205. CrossRef Medline

Steinhauer K, Drury JE (2012) On the early left-anterior negativity (ELAN) in syntax studies. Brain Lang 120:135-162. CrossRef Medline

Tabullo A, Sevilla Y, Pasqualetti G, Vernis S, Segura E, Yorio A, Zanutto S, Wainselboim A (2011) Expectancy modulates a late positive ERP in an artificial grammar task. Brain Res 1373:131-143. CrossRef Medline

Ullman MT (2001) A neurocognitive perspective on language: the declarative/procedural model. Nat Rev Neurosci 2:717-726. CrossRef Medline

Wilson LB, Tregellas JR, Slason E, Pasko BE, Rojas DC (2011) Implicit phonological priming during visual word recognition. Neuroimage 55:724-731. CrossRef Medline

Woods DL, Hillyard SA, Courchesne E, Galambos R (1980) Electrophysiological signs of split-second decision-making. Science 207:655657. CrossRef Medline 